\title{
Hand grip strength is associated with forced expiratory volume in I second among subjects with COPD: report from a population-based cohort study
}

\author{
This article was published in the following Dove Press journal: \\ International Journal of COPD \\ 7 October 2016 \\ Number of times this article has been viewed
}

\section{Viktor Johansson \\ Strandkvist ${ }^{1,2}$ \\ Helena Backman ${ }^{2}$ \\ Jenny Röding' \\ Caroline Stridsman ${ }^{3}$ \\ Anne Lindberg ${ }^{4}$}

'Division of Health and Rehabilitation, Department of Health Science, Luleå University of Technology, Luleå, ${ }^{2}$ Division of Occupational and Environmental Medicine, Department of Public Health and Clinical Medicine, The Obstructive Lung disease in Northern Sweden Unit, Umeå University, Umeå, ${ }^{3}$ Division of Nursing, Department of Health Science, Luleå University of Technology, Luleå, ${ }^{4}$ Division of Medicine, Department of Public Health and Clinical Medicine, Umeå University, Umeå, Sweden
Correspondence: Anne Lindberg Division of Medicine, Department of Public Health and Clinical Medicine, Umeå University, 90187 Umeå, Sweden Mob +4670574 II 70

Email anne.lindberg@algmed.se
Background: Cardiovascular diseases and skeletal muscle dysfunction are common comorbidities in COPD. Hand grip strength (HGS) is related to general muscle strength and is associated with cardiovascular disease and all-cause mortality, while the results from small selected COPD populations are contradictory. The aim of this population-based study was to compare HGS among the subjects with and without COPD, to evaluate HGS in relation to COPD severity, and to evaluate the impact of heart disease.

Subjects and methods: Data were collected from the Obstructive Lung disease in Northern Sweden COPD study, where the subjects with and without COPD have been invited to annual examinations since 2005. In 2009-2010, 441 subjects with COPD (postbronchodilator forced expiratory volume in 1 second $\left[\mathrm{FEV}_{1}\right] /$ vital capacity $\left.<0.70\right)$ and 570 without $\mathrm{COPD}$ participated in structured interviews, spirometry, and measurements of HGS.

Results: The mean HGS was similar when comparing subjects with and without COPD, but those with heart disease had lower HGS than those without. When compared by Global Initiative for Chronic Obstructive Lung Disease (GOLD) grades, the subjects with GOLD 3-4 had lower HGS than those without COPD in both sexes (females $21.4 \mathrm{~kg}$ vs $26.9 \mathrm{~kg}, P=0.010$; males $41.5 \mathrm{~kg}$ vs $46.3 \mathrm{~kg}, P=0.038$ ), and the difference persisted also when adjusted for confounders. Among the subjects with COPD, HGS was associated with $\mathrm{FEV}_{1} \%$ of predicted value but not heart disease when adjusted for height, age, sex, and smoking habits, and the pattern was similar among males and females.

Conclusion: In this population-based study, the subjects with GOLD 3-4 had lower HGS than the subjects without COPD. Among those with COPD, HGS was associated with $\mathrm{FEV}_{1} \%$ of predicted value but not heart disease, and the pattern was similar in both sexes.

Keywords: muscle strength, muscle strength dynamometer, pulmonary disease, COPD, heart diseases, epidemiology

\section{Introduction}

COPD causes a significant burden of disease throughout the world. ${ }^{1}$ Comorbidities are common among the subjects with COPD whereof cardiovascular diseases are the most frequent. ${ }^{2,3}$ Skeletal muscle dysfunction is another concomitant condition (related to exercise limitation, ${ }^{4,5}$ muscle fiber atrophy, and muscle fiber shift ${ }^{6}$ ) important to consider when evaluating physical disability in COPD. Muscle dysfunction may, however, be different in respiratory and peripheral muscles among the subjects with COPD; respiratory muscles need to adapt to increased working load due to increased 
work of breathing, while the skeletal muscle dysfunction in upper and lower extremities is more complex. ${ }^{7}$

Muscle strength, assessed as hand grip strength (HGS), was a risk marker for cardiovascular disease, and a decline in HGS predicted all-cause mortality in a large multinational population-based study. ${ }^{8}$ However, there was no association between HGS and risk of hospital admission for COPD, ${ }^{8}$ but an association between HGS and mortality among the subjects with COPD has recently been discussed. ${ }^{9}$ It has also been reported that HGS is associated with muscle strength in both upper and lower limbs among the subjects with moderate-to-very severe COPD. ${ }^{10}$ Although there are a few studies of HGS in selected COPD populations, the results are somewhat contradictory. In a relatively large primary care study, the subjects with COPD had lower HGS compared with a healthy control group, ${ }^{11}$ while in another study, HGS was similar among the subjects with moderate-to-severe COPD and healthy controls. ${ }^{12}$ there was no correlation between HGS and lung function, assessed as forced expiratory volume in 1 second $\left(\mathrm{FEV}_{1} \%\right)$ of predicted value, among the subjects with moderate-to-very severe COPD. ${ }^{10,13}$ These contradictory results are most probably due to differences in the selection of study population and the well-known underdiagnosis of COPD. ${ }^{14}$ HGS in relation to COPD disease severity and the impact of cardiovascular comorbidity on HGS among the subjects with COPD have hardly been evaluated in population-based studies.

The aim of this population-based study was to compare HGS among the subjects with and without COPD by COPD severity. Secondary aims were to evaluate HGS in relation to reference values and to evaluate the impact of heart disease in relation to HGS among the subjects with and without COPD.

\section{Subjects and methods Study design and study population}

The population-based Obstructive Lung disease in Northern Sweden (OLIN) COPD study in 2002-2004 recruited 993 subjects with and 993 age- and sex-matched referents without obstructive lung function impairment (COPD and nonCOPD). ${ }^{15}$ The study population $(\mathrm{N}=1,986)$ has since 2005 been invited to annual examinations, including structured interviews and spirometry.

The current article is based on data collected during 2009 and 2010 when measurements of HGS were made in addition to the basic program. The study population includes 1,011 subjects (COPD, $n=441$ ) with complete data from structured interview, spirometry, and HGS. Written informed consent was obtained from all study participants. The regional ethics committee at Umeå University, Sweden, approved the study.

\section{Questionnaire and definitions}

The interview included previously validated questions on respiratory symptoms, developed mainly from the British Medical Research Council (MRC) questionnaire, ${ }^{16-18}$ including the modified MRC dyspnea scale (0-4), ${ }^{19}$ and in addition questions regarding smoking habits, respiratory diseases, and comorbidities such as heart diseases.

"Any respiratory symptom" was defined as at least one of persistent cough, productive cough, recurrent wheeze, or dyspnea (modified MRC $\geq 2$ ). Those with smoking habits were divided into nonsmokers, ex-smokers (stopped since at least 12 months), and smokers. Heart disease was defined as a history of at least one of the following diseases: angina pectoris, myocardial infarction, heart failure, coronary artery bypass, or percutaneous coronary intervention procedure. Body mass index was calculated as weight $/$ height $^{2}$ $\left(\mathrm{kg} / \mathrm{m}^{2}\right)$ and classified into four groups: $<18.5 \mathrm{~kg} / \mathrm{m}^{2}$, $18.5-24.9 \mathrm{~kg} / \mathrm{m}^{2}, 25-29.9 \mathrm{~kg} / \mathrm{m}^{2}$, and $\geq 30 \mathrm{~kg} / \mathrm{m}^{2}{ }^{20}$

\section{Spirometry}

The spirometry was performed using a dry volume spirometer, the Mijnhardt Vicatest, according to standards set by European Respiratory Society/American Thoracic Society ${ }^{21}$ but with a repeatability criterion of $\leq 5 \%$. COPD was defined as $\mathrm{FEV}_{1} /$ (best of slow vital capacity [SVC] or forced vital capacity $[\mathrm{FVC}])<0.70$, using the highest value pre- or postbronchodilatation, and severity-grading was based on $\mathrm{FEV}_{1} \%$ of predicted value according to the Global Initiative for Chronic Obstructive Lung Disease (GOLD) document, GOLD 1-4. ${ }^{22}$ Non-COPD was defined as $\mathrm{FEV}_{1} /($ best of $\mathrm{SVC}$ or $\mathrm{FVC}) \geq 0.70$, including also the subjects with restrictive spirometric pattern (RSP; $\mathrm{FEV}_{1} /[$ best of SVC or FVC] $\geq 0.70$ and $\mathrm{FVC}<80 \%$ of predicted). Reversibility testing was performed if $\mathrm{FEV}_{1} /$ (best of SVC or FVC) $<0.70$ or $\mathrm{FEV}_{1}<80 \%$ of predicted. The OLIN reference values for spirometry were used. ${ }^{23}$

\section{Hand grip strength}

HGS was measured by a handheld dynamometer, Jamar ${ }^{\circledR}$ (Sammons Preston Rolyan, Boilingbrook, IL, USA), in kilogram. ${ }^{24}$ The participants were instructed to sit down with their elbows flexed in an angle of $90^{\circ}$ and the dynamometer in hand in a supine position. Three attempts were performed with each hand, and the highest value was used for analysis. Two different meta-analyses provided reference values 
for grip strength in the general population (mean and 95\% confidence intervals [CIs]), one for adults up to 75 years of age $^{25}$ and the other for those older than 75 years. ${ }^{26}$

\section{Statistical analysis}

Statistical analyses were performed with Statistical Package for the Social Sciences, Version 22 (IBM Corporation, Armonk, NY, USA). $P$-values $<0.05$ were considered statistically significant. A low frequency of the subjects in GOLD 3 and 4 prompted a merge into GOLD 3-4. The Student's $t$-test was utilized to compare mean HGS values between groups. To analyze HGS in relation to reference values, the proportion below the mean reference value and the proportion below the $95 \%$ CI of the mean were compared between those with and without COPD using chi-squared test. Differences in mean HGS between non-COPD and COPD and non-COPD and GOLD grades were analyzed in multiple linear regression models adjusted for sex, age, height, heart disease, and smoking habits. Separate multiple linear regression analyses of the association between HGS and heart disease and $\mathrm{FEV}_{1} \%$ of predicted value were performed among the subjects with and without COPD, respectively. All regression analyses were performed with $\mathrm{HGS}$ as dependent variable in models, including all subjects (adjusted for sex) as well as stratified by sex.

\section{Results \\ Basic characteristics}

The basic characteristics of the study population, comparing non-COPD and COPD by sex, are shown in Table 1 . In both sexes, any respiratory symptoms were significantly more common among COPD subjects, while heart disease was equally common in COPD and non-COPD subjects. The distribution of $\operatorname{sex}(n=$ females/males) by GOLD grades was $\mathrm{n}=102 / 92$ in GOLD $1, \mathrm{n}=86 / 132$ in GOLD 2, and $\mathrm{n}=7 / 22$ in GOLD 3-4.

\section{HGS in COPD}

There was no difference in HGS when comparing COPD and non-COPD subjects among males, while females with COPD had borderline significantly lower HGS than those without (Table 1). When comparing non-COPD with each of the GOLD grades, HGS was significantly lower in GOLD 3-4 in both sexes (Figure 1 and Table S1). Figure 1 illustrates the consistently higher values among males compared to females. The results were also similar when excluding subjects with RSP from the non-COPD group (Table S2).

The subjects with COPD had nonsignificantly lower mean HGS than the non-COPD subjects when adjusted for sex, age, height, heart disease, and smoking habits (Table S3 $)$, with a similar pattern in both sexes. Among the subjects with $\mathrm{COPD}$, there was a significant correlation between $\mathrm{FEV}_{1} \%$ of predicted value and HGS among males (Pearson's $r=0.163$, $r^{2}=0.027, P=0.010$ ), but not among females (Pearson's $\left.r=0.074, r^{2}=0.005, P=0.315\right)$.

\section{HGS and reference values}

The HGS values among males and females with and without COPD in relation to reference values are plotted by age in Figure 2A-D, visualizing also subjects with concomitant

Table I Basic characteristics comparing the subjects with and without COPD among females and males, respectively

\begin{tabular}{|c|c|c|c|c|c|c|}
\hline \multirow[t]{2}{*}{ Variables } & \multicolumn{3}{|l|}{ Females } & \multicolumn{3}{|l|}{ Males } \\
\hline & $\begin{array}{l}\text { Non-COPD } \\
(n=255)\end{array}$ & $\begin{array}{l}\text { COPD } \\
(n=195)\end{array}$ & $P$-value ${ }^{a}$ & $\begin{array}{l}\text { Non-COPD } \\
(n=3 \mid 5)\end{array}$ & $\begin{array}{l}\text { COPD } \\
(n=246)\end{array}$ & $P$-value ${ }^{a}$ \\
\hline Age (years), mean (SD) & $67.8(10.3)$ & $69.5(9.7)$ & 0.074 & $67.8(10.2)$ & $68.3(9.0)$ & 0.616 \\
\hline Smoker, n (\%) & $26(10.2)$ & $40(20.6)$ & & $22(7.0)$ & $62(25.2)$ & \\
\hline Ex smoker, n (\%) & $93(36.5)$ & $82(42.1)$ & & I 54 (48.9) & 135 (54.9) & \\
\hline Non smoker, n (\%) & $136(53.3)$ & $73(20.9)$ & 0.001 & $139(44.1)$ & $49(20.0)$ & $<0.001$ \\
\hline Height (cm), mean (SD) & $160.2(6.7)$ & $160.5(6.2)$ & 0.602 & I73.7 (7.5) & $174.6(6.6)$ & 0.127 \\
\hline BMI $\left(\mathrm{kg} / \mathrm{m}^{2}\right)$, mean $(\mathrm{SD})$ & $27.9(4.7)$ & $26.7(4.5)$ & 0.007 & $27.6(3.7)$ & 27.1 (3.9) & 0.141 \\
\hline$<18.5, \mathrm{n}(\%)$ & $4(1.6)$ & $2(1.0)$ & & $0(0.0)$ & I $(0.4)$ & \\
\hline 18.5-24.9, n (\%) & $67(26.3)$ & $84(43.1)$ & & 72 (22.9) & $72(29.3)$ & \\
\hline 25-29.9, n (\%) & I I 6 (45.5) & $68(34.9)$ & & 177 (56.2) & 130 (52.8) & \\
\hline$\geq 30, \mathrm{n}(\%)$ & $68(26.7)$ & $4 \mid(2 \mid .0)$ & 0.003 & $66(21.0)$ & $43(17.5)$ & 0.201 \\
\hline $\mathrm{FEV}, \%$ of predicted value, mean (SD) & $97.2(14.3)$ & $80.1(16.6)$ & $<0.001$ & 93.7 (13.3) & $74.6(15.7)$ & $<0.001$ \\
\hline Any respiratory symptoms, n (\%) & $125(49.0)$ & $131(67.2)$ & $<0.001$ & $162(5 \mathrm{l} .4)$ & $183(74.4)$ & $<0.001$ \\
\hline Heart disease, n (\%) & $32(12.5)$ & $31(15.9)$ & 0.343 & $65(20.6)$ & $46(18.7)$ & 0.490 \\
\hline HGS (kg), mean (SD) & $26.9(6.7)$ & $25.8(5.9)$ & 0.053 & $46.3(10.5)$ & 45.9 (9.9) & 0.676 \\
\hline
\end{tabular}

Notes: ${ }^{a}$ Comparing non-COPD and COPD. P-values $<0.05$ are given in bold.

Abbreviations: SD, standard deviation; BMI, body mass index; FEV \%, forced expiratory volume in I second, percentage of predicted value; HGS, hand grip strength. 


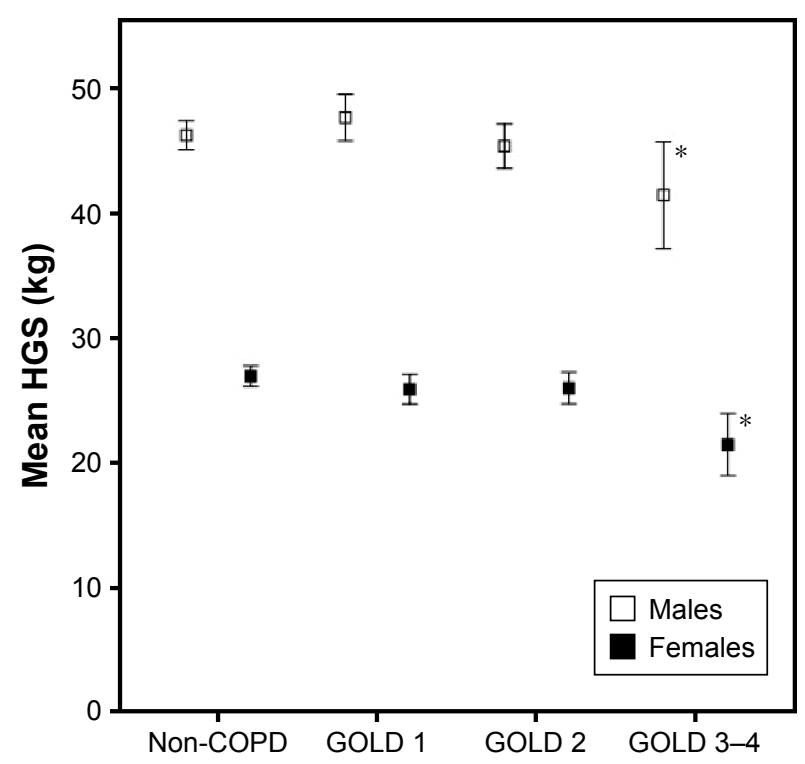

Figure I HGS (mean, kg) stratified by sex in subjects with non-COPD and COPD by GOLD grades (bars represent $95 \% \mathrm{Cls}$ ).

Note: $* P<0.05$ when comparing the subjects with GOLD 3-4 with the subjects with non-COPD.

Abbreviations: HGS, hand grip strength; GOLD, Global Initiative for Chronic Obstructive Lung Disease; $\mathrm{Cl}$, confidence interval.
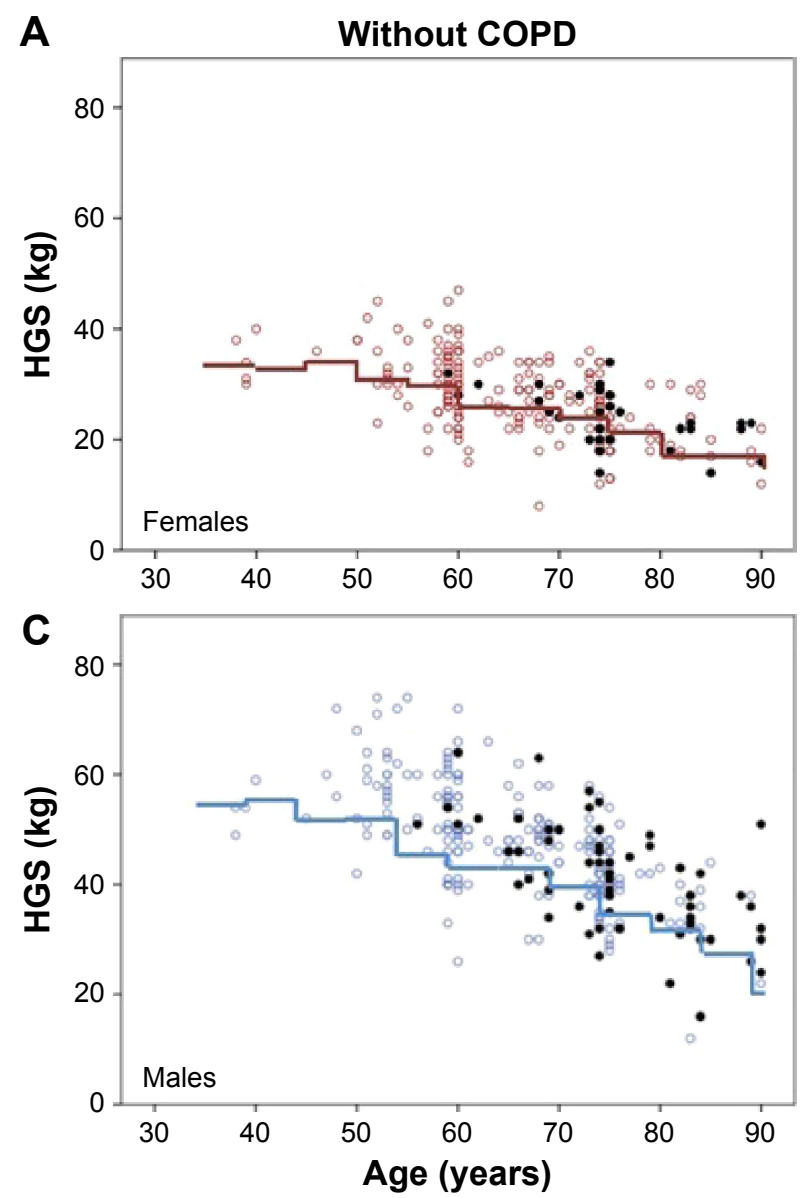

heart disease. The proportion of the subjects below the reference value was similar in the subjects with and without COPD in both sexes (females $40 \%$ vs $37.3 \%, P=0.553$; males $21.1 \%$ vs $17.8 \%, P=0.316$ ). The proportion of the subjects with HGS below the reference value among those with heart disease was nonsignificantly higher among the subjects with COPD than among the subjects without COPD, in females $48.4 \%$ vs $34.4 \%(P=0.259)$ and in males $28.3 \%$ vs $20 \%$ $(P=0.311)$. Corresponding comparisons were also made using the cutoff below the $95 \% \mathrm{CI}$ of the reference values with similar pattern in all analyses.

\section{Factors associated with HGS}

In both sexes, both in COPD and non-COPD, the subjects with heart disease had significantly lower HGS than those without heart disease (Table 2). In a multiple linear regression model, HGS was significantly associated with $\mathrm{FEV}_{1} \%$ of predicted value but not heart disease among the subjects with COPD when adjusted for age, sex, and height (Table 3). In similar analyses stratified by sex, HGS was associated

B
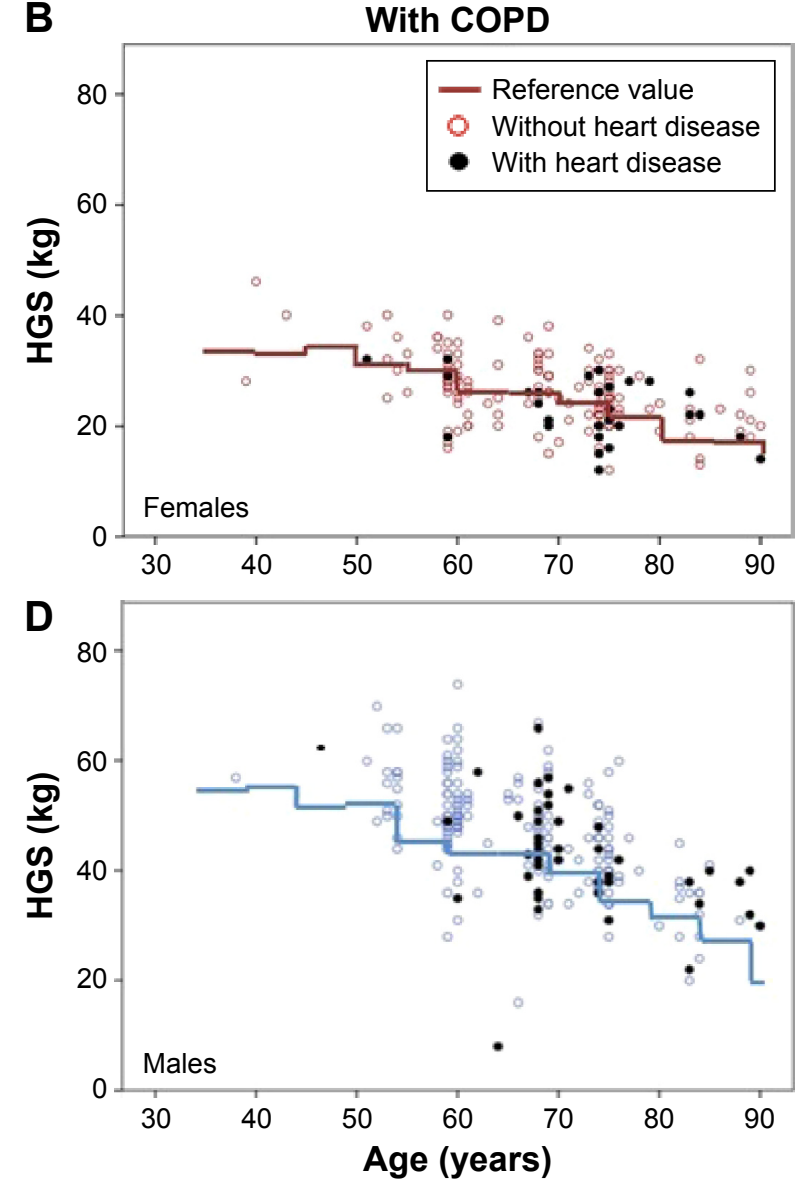

Figure 2 HGS $(\mathrm{kg})$ among the subjects with (black) and without heart disease plotted by age among (A) females without COPD, (B) females with COPD, (C) males without COPD, and (D) males with COPD.

Abbreviation: HGS, hand grip strength. 
Table 2 Comparisons of mean HGS between the subjects with or without heart disease and with or without COPD

\begin{tabular}{|c|c|c|c|c|c|c|}
\hline \multirow[t]{3}{*}{ Categories } & \multicolumn{3}{|l|}{ Females } & \multicolumn{3}{|l|}{ Males } \\
\hline & $\begin{array}{l}\text { No heart disease } \\
(n=353)\end{array}$ & $\begin{array}{l}\text { Heart disease } \\
(n=63)\end{array}$ & $P$-value ${ }^{a}$ & $\begin{array}{l}\text { No heart disease } \\
(n=390)\end{array}$ & $\begin{array}{l}\text { Heart disease } \\
(n=\mid I I)\end{array}$ & $P$-value ${ }^{a}$ \\
\hline & Mean (SD) HGS & Mean (SD) HGS & & Mean (SD) HGS & Mean (SD) HGS & \\
\hline Non-COPD & $27.6(6.8)$ & $23.7(5.1)$ & 0.002 & $48.3(9.9)$ & $40.7(10.2)$ & $<0.001$ \\
\hline COPD & $26.3(6.0)$ & $22.9(5.3)$ & 0.005 & $46.9(9.8)$ & $41.9(9.9)$ & 0.003 \\
\hline$P$-value & $0.05 \mathrm{I}^{\mathrm{b}}$ & $0.566^{c}$ & & $0.152^{\mathrm{b}}$ & $0.536^{c}$ & \\
\hline
\end{tabular}

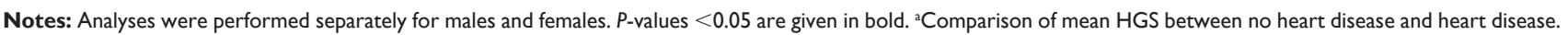
${ }^{b}$ Comparison of mean HGS between non-COPD and COPD in no heart disease. ${ }^{\circ}$ Comparison of mean HGS between non-COPD and COPD in heart disease.

Abbreviations: HGS, hand grip strength; SD, standard deviation.

with $\mathrm{FEV}_{1} \%$ of predicted value among males, but not among females with COPD. When smoking habits was added to the model, the association between $\mathrm{HGS}$ and $\mathrm{FEV}_{1} \%$ of predicted value remained in the total COPD population, but not among males. Similar analyses performed in the non-COPD group yielded no significant findings (Table 3 ).

\section{Discussion}

In this population-based study, there was no significant difference in HGS when comparing the subjects with and without COPD. However, when comparing the subjects with non-COPD and COPD by GOLD grades, the subjects with GOLD 3-4 had significantly lower mean HGS. Furthermore, those with heart disease had lower mean HGS compared with those without. The significantly lower HGS among the subjects with GOLD 3-4 compared with non-COPD subjects persisted also after adjustment for age, height, sex, smoking habits, and heart disease, and the pattern was similar in both sexes. In further analyses among those with COPD, HGS was associated with disease severity, assessed as $\mathrm{FEV}_{1} \%$ of predicted value, but not with heart disease, independent of sex, age, height and smoking habits.

Previous studies are contradictory; some have shown similar HGS among the subjects with and without COPD, ${ }^{5,12,13}$ while others have shown lower HGS in the subjects with
COPD. ${ }^{11}$ These referred studies were register based and included selected study populations of mainly subjects with GOLD 2 or higher, while our population-based COPD cohort was dominated by the subjects with GOLD 1 and GOLD 2. The subjects with GOLD 3-4 had significantly lower HGS when compared with the subjects with non-COPD, and the observed difference, $>4 \mathrm{~kg}$ force, may be of clinical importance. However, each of the GOLD grades includes a rather wide range of $\mathrm{FEV}_{1} \%$ of predicted value, which may, as a continuous variable, be more sensitive when evaluating HGS in relation to COPD severity. Actually, in COPD, decreasing value of $\mathrm{FEV}_{1} \%$ predicted was associated with lower HGS, which persisted also after adjustment for confounders.

It has been shown that patients with heart disease have less strength in lower extremities than those without. ${ }^{27,28}$ Heart disease was associated with low HGS also in a populationbased study, ${ }^{29}$ and impaired heart function was associated with lower HGS in patients with moderate-to-severe COPD. ${ }^{30}$ In contrast, those with cardiovascular disease had similar HGS as those without in a study of elderly volunteers, ${ }^{31}$ and low HGS was not associated with cardiovascular events in a population-based study. ${ }^{32}$ The selection of study populations, different definitions of heart disease, and different approaches to or lack of age adjustments may contribute to contradictory results. In our study, the subjects with heart

Table 3 Multiple linear regression models analyzing the association between HGS and $\mathrm{FEV}, \%$ of predicted value and heart disease among the subjects with and without COPD, respectively, adjusting for age and height

\begin{tabular}{|c|c|c|c|c|c|c|c|c|c|}
\hline \multirow{2}{*}{$\begin{array}{l}\text { Categories/ } \\
\text { variables }\end{array}$} & \multicolumn{3}{|c|}{ Females } & \multicolumn{3}{|l|}{ Males } & \multicolumn{3}{|c|}{ Total study population } \\
\hline & B & $95 \% \mathrm{Cl}$ & $P$-value & B & $95 \% \mathrm{Cl}$ & $P$-value & B & $95 \% \mathrm{Cl}$ & $P$-value \\
\hline \multicolumn{10}{|l|}{ Non-COPD } \\
\hline FEV $\%$ pred & 0.02 & $(-0.03-0.07)$ & 0.468 & 0.03 & $(-0.03-0.10)$ & 0.299 & 0.03 & $(-0.01-0.08)$ & 0.115 \\
\hline Heart disease & -0.36 & $(-2.48-1.76)$ & 0.738 & -0.44 & $(-2.65-1.78)$ & 0.697 & -0.78 & $(-2.37-0.82)$ & 0.340 \\
\hline \multicolumn{10}{|l|}{ COPD } \\
\hline $\mathrm{FEV}_{1} \%$ pred & 0.02 & $(-0.02-0.07)$ & 0.290 & 0.07 & $(0.01-0.14)$ & 0.047 & 0.05 & $(0.01-0.09)$ & 0.020 \\
\hline Heart disease & -1.36 & $(-3.35-0.63)$ & 0.179 & -0.67 & $(-3.40-2.06)$ & 0.629 & -1.20 & $(-3.00-0.60)$ & 0.180 \\
\hline
\end{tabular}

Note: $P$-values $<0.05$ are given in bold.

Abbreviations: HGS, hand grip strength; FEV \% pred, forced expiratory volume in I second, percentage of predicted value; $B$, beta coefficient from multiple linear regression models with HGS as a dependent variable, adjusted for age, height, heart disease, FEV,\% pred, and in the total study population also adjusted for sex; Cl, confidence interval. 
disease had lower HGS compared to those without in both COPD and non-COPD, but these results lost significance when adjusted for age and other possible confounders. The adjusted analyses indicate that heart disease is of less importance for HGS than disease severity among the subjects with COPD in the population.

Our hypothesis that the proportion of the subjects with HGS below the reference value (or 95\% CI) should be higher among the subjects with COPD than without COPD was rejected. We used the Bohannon reference values for HGS measured with Jamar ${ }^{\circledR} \cdot{ }^{25,26}$ While they provide multinational data with age groups corresponding to our study, but it seems as these reference values may be too low for our population, especially among males as illustrated by Figure 1 . There are more recently published reference values for HGS available based on a bigger sample size and in which the analysis accounts also for height, ${ }^{33}$ but these are restricted to ages 73 years and younger and are thus not applicable to our study population, including many elderly. We used the best effort of three attempts per hand in the same manners as the previously cited multinational population-based study. ${ }^{8}$ The mean of the attempts has been used by others, ${ }^{13,30,34}$ but there is a risk of underestimating the maximum strength of individuals with low muscular endurance, unable to produce full strength for all three attempts.

The cause of muscle dysfunction among individuals with COPD is most likely a complex interaction of many factors and may also be related to physical inactivity. ${ }^{7,35}$ A close relationship between HGS and exercise capacity, assessed as 6 minutes walking test, and hyperinflation has been shown among 27 subjects with moderate and severe COPD. ${ }^{34}$ Measuring HGS is a relatively simple method not overly dependent on time, equipment, or effort, ${ }^{24}$ which may be used in daily practice to assess muscle function among the subjects with COPD. Further studies on HGS may give us an easy-to-use tool to assess and follow the physical aspects of the disease process among the subjects with COPD, also contributing to identify the need for and also to evaluate the outcome of pulmonary rehabilitation.

The strength of this study is that it includes a large population-based COPD cohort, with a distribution by GOLD grades, corresponding well to the findings of other population-based studies. ${ }^{36}$ Well-validated methods were used; the diagnosis of COPD was based on postbronchodilator spirometry, and HGS was measured by the hand dynamometer Jamar ${ }^{\circledR}$. Even though a population-based COPD cohort included only a few percent of the subjects with GOLD 3-4, the statistical power was still large enough to demonstrate a lower HGS in this group when compared to the subjects without COPD. A healthy survivor effect may have affected the results, as the mortality since baseline is higher among those with COPD; ${ }^{15,37}$ thus, the observed associations in the current study may actually be underestimated.

There also exist study limitations. The fixed ratio criterion for airway obstruction may contribute to an overdiagnosis of COPD among elderly, and the lower limit of normal is now recommended to define COPD in epidemiological studies. ${ }^{38}$ However, the current study was designed just after the shift of the millennium when the first GOLD document was launched and the fixed ratio criterion was generally accepted, and still most of the current treatment guidelines are based on the fixed ratio criterion. Another limitation is that heart disease was self-reported and not confirmed by medical records, meaning that we also lack information of physiological measures of heart disease, such as echocardiography, including assessment of ejection fraction and exercise electrocardiogram. Furthermore, we cannot exclude that patients with sternotomy and a phrenic injury affecting lung function are included; however, the expected number is low and may thus not have affected our main results. The non-COPD group also includes the subjects with RSP, known to be associated with increased mortality and cardiovascular morbidity, ${ }^{39,40}$ and the observed differences when comparing non-COPD and GOLD-grades were even more obvious when excluding the subjects with RSP.

\section{Conclusion}

There was no difference in HGS when comparing the subjects with and without COPD in this population-based study, while those with heart disease had lower HGS than those without. However, HGS was associated with COPD disease severity, assessed as GOLD grading as well as $\mathrm{FEV}_{1} \%$ of predicted value, also when adjusted for confounders, while the negative impact of heart disease lost its significance. The pattern was similar in both sexes. Further studies are needed to evaluate HGS as a possible instrument for evaluating physical aspects of the disease process among the subjects with COPD.

\section{Acknowledgments}

Financial support from the Swedish Heart \& Lung Foundation; ALF-funds from Umeå University, Sweden; Visare Norr; and the County Council of Norrbotten is gratefully acknowledged. The authors acknowledge Professor Bo Lundbäck, the initiator of the OLIN studies who also contributed to the design of the OLIN COPD study, and Eva 
Rönmark, the current head of the OLIN study. The authors also thank the research assistants Ann-Christine Jonsson, Britt-Marie Eklund, and Sigrid Sundberg for collecting the data and Ola Bernhoff for administrating the database. The authors also acknowledge the great collaboration with Luleå University of Technology.

\section{Author contributions}

All authors contributed toward data analysis, drafting and critically revising the paper and agree to be accountable for all aspects of the work.

\section{Disclosure}

The authors report no conflicts of interest in this work.

\section{References}

1. Rycroft CE, Heyes A, Lanza L, Becker K. Epidemiology of chronic obstructive pulmonary disease: a literature review. Int J Chron Obstruct Pulmon Dis. 2012;7:457-494.

2. Gershon AS, Mecredy GC, Guan J, Victor JC, Goldstein R, To T. Quantifying comorbidity in individuals with COPD: a population study. Eur Respir J. 2015;45(1):51-59.

3. Lindberg A, Larsson LG, Ronmark E, Lundback B. Co-morbidity in mild-to-moderate COPD: comparison to normal and restrictive lung function. COPD. 2011;8(6):421-428.

4. O'Donnell DE, Gebke KB. Activity restriction in mild COPD: a challenging clinical problem. Int J Chron Obstruct Pulmon Dis. 2014;9: 577-588.

5. Gosselink R, Troosters T, Decramer M. Peripheral muscle weakness contributes to exercise limitation in COPD. Am J Respir Crit Care Med. 1996;153(3):976-980.

6. Whittom F, Jobin J, Simard PM, et al. Histochemical and morphological characteristics of the vastus lateralis muscle in patients with chronic obstructive pulmonary disease. Med Sci Sports Exerc. 1998;30(10): 1467-1474.

7. Donaldson AV, Maddocks M, Martolini D, Polkey MI, Man WD-C. Muscle function in COPD: a complex interplay. Int $J$ Chron Obstruct Pulmon Dis. 2012;7:523-535.

8. Leong DP, Teo KK, Rangarajan S, et al; Prospective Urban Rural Epidemiology (PURE) Study Investigators. Prognostic value of grip strength: findings from the prospective urban rural epidemiology (PURE) study. Lancet. 2015;386(9990):266-273.

9. Burtin C, Ter Riet G, Puhan MA, et al. Handgrip weakness and mortality risk in COPD: a multicentre analysis. Thorax. 2016;71(1):86-87.

10. Marino DM, Marrara KT, Ike D, De Oliveira AD Jr, Jamami M, Di Lorenzo VA. Study of peripheral muscle strength and severity indexes in individuals with chronic obstructive pulmonary disease. Physiother Res Int. 2010;15(3):135-143.

11. Eisner MD, Blanc PD, Yelin EH, et al. COPD as a systemic disease: impact on physical functional limitations. Am J Med. 2008;121(9):789-796.

12. Gosselink R, Troosters T, Decramer M. Distribution of muscle weakness in patients with stable chronic obstructive pulmonary disease. J Cardiopulm Rehabil. 2000;20(6):353-360.

13. Hallin R, Janson C, Arnardottir RH, et al. Relation between physical capacity, nutritional status and systemic inflammation in COPD. Clin Respir J. 2011;5(3):136-142.

14. Lamprecht B, Soriano JB, Studnicka M, et al; BOLD Collaborative Research Group, the EPI-SCAN Team, the PLATINO Team, and the PREPOCOL Study Group. Determinants of underdiagnosis of COPD in national and international surveys. Chest. 2015;148(4): 971-985.
15. Lindberg A, Lundback B. The Obstructive Lung Disease in Northern Sweden Chronic Obstructive Pulmonary Disease Study: design, the first year participation and mortality. Clin Respir J. 2008;2(1): 64-71.

16. Lindberg A, Bjerg A, Ronmark E, Larsson LG, Lundback B. Prevalence and under diagnosis of COPD by disease severity and the attributable fraction of smoking report from the Obstructive Lung Disease in Northern Sweden studies. Respir Med. 2006;100(2):264-272.

17. Jyrki-Tapani K, Sovijarvi A, Lundback B. Chronic obstructive pulmonary disease in Finland: prevalence and risk factors. COPD. 2005;2(3): 331-339.

18. Lundback B, Ronmark E, Jonsson E, Larsson K, Sandstrom T. Incidence of physician-diagnosed asthma in adults - a real incidence or a result of increased awareness? Report from the Obstructive Lung Disease in Northern Sweden studies. Respir Med. 2001;95(8):685-692.

19. Mahler DA, Wells CK. Evaluation of clinical methods for rating dyspnea. Chest. 1988;93(3):580-586.

20. WHO. Obesity: Preventing and Managing the Global Epidemic. Geneva: World Health Organization; 2000. [WHO Technical report series 894].

21. Miller MR, Hankinson J, Brusasco V, et al; ATS/ERS Task Force Standardisation of spirometry. Eur Respir J. 2005;26(2):319-338.

22. Global Initiative for Chronic Obstructive Lung Disease (GOLD) [homepage on the Internet]. From the Global Strategy for the Diagnosis, Management and Prevention of COPD; 2016 [updated December 2015]. Available from: http://goldcopd.org/. Accessed May 23, 2016.

23. Backman H, Lindberg A, Oden A, et al. Reference values for spirometry report from the Obstructive Lung Disease in Northern Sweden studies. Eur Clin Respir J. 2015;2 [eCollection 2015].

24. Mathiowetz V, Weber K, Volland G, Kashman N. Reliability and validity of grip and pinch strength evaluations. J Hand Surg Am. 1984;9(2): 222-226.

25. Bohannon RW, Peolsson A, Massy-Westropp N, Desrosiers J, BearLehman J. Reference values for adult grip strength measured with a Jamar dynamometer: a descriptive meta-analysis. Physiotherapy. 2006; 92(1):11-15.

26. Bohannon RW, Bear-Lehman J, Desrosiers J, Massy-Westropp N, Mathiowetz V. Average grip strength: a meta-analysis of data obtained with a Jamar dynamometer from individuals 75 years or more of age. $J$ Geriatr Phys Ther. 2007;30(1):28-30.

27. Harrington D, Anker SD, Chua TP, et al. Skeletal muscle function and its relation to exercise tolerance in chronic heart failure. $J \mathrm{Am}$ Coll Cardiol. 1997;30(7):1758-1764.

28. Baum K, Hildebrandt U, Edel K, et al. Comparison of skeletal muscle strength between cardiac patients and age-matched healthy controls. Int J Med Sci. 2009;6(4):184-191.

29. Stenholm S, Tiainen K, Rantanen T, et al. Long-term determinants of muscle strength decline: prospective evidence from the 22-year mini-Finland follow-up survey. J Am Geriatr Soc. 2012;60(1): $77-85$.

30. Cortopassi F, Divo M, Pinto-Plata V, Celli B. Resting handgrip force and impaired cardiac function at rest and during exercise in COPD patients. Respir Med. 2011;105(5):748-754.

31. Baumgartner RN, Waters DL, Gallagher D, Morley JE, Garry PJ. Predictors of skeletal muscle mass in elderly men and women. Mech Ageing Dev. 1999;107(2):123-136.

32. Amaral Cde A, Portela MC, Muniz PT, Farias Edos S, Araujo TS, Souza OF. Association of handgrip strength with self-reported diseases in adults in Rio Branco, Acre State, Brazil: a population-based study. Cad Saude Publica. 2015;31(6):1313-1325.

33. Spruit MA, Sillen MJ, Groenen MT, Wouters EF, Franssen FM. New normative values for handgrip strength: results from the UK Biobank. J Am Med Dir Assoc. 2013;14(10):775.e5-775.e11.

34. Cortopassi F, Celli B, Divo M, Pinto-Plata V. Longitudinal changes in handgrip strength, hyperinflation, and 6-minute walk distance in patients with COPD and a control group. Chest. 2015;148(4): 986-994. 
35. Maltais F, Decramer M, Casaburi R, et al; ATS/ERS Ad Hoc Committee on Limb Muscle Dysfunction in COPD. An official American Thoracic Society/European Respiratory Society statement: update on limb muscle dysfunction in chronic obstructive pulmonary disease. Am J Respir Crit Care Med. 2014;189(9):e15-e62.

36. Hansen JG, Pedersen L, Overvad K, Omland O, Jensen HK, Sorensen HT. The Prevalence of chronic obstructive pulmonary disease among Danes aged 45-84 years: population-based study. COPD. 2008;5(6): $347-352$.

37. Lindberg A, Sawalha S, Hedman L, Larsson LG, Lundback B, Ronmark E. Subjects with COPD and productive cough have an increased risk for exacerbations and death. Respir Med. 2015;109(1): $88-95$.
38. Bakke PS, Rönmark E, Eagan T, et al; European Respiratory Society Task Force. Recommendations for epidemiological studies on COPD. Eur Respir J. 2011;38(6):1261-1277.

39. Guerra S, Sherrill DL, Venker C, Ceccato CM, Halonen M, Martinez FD. Morbidity and mortality associated with the restrictive spirometric pattern: a longitudinal study. Thorax. 2010;65(6):499-504.

40. Godfrey MS, Jankowich MD. The vital capacity is vital: epidemiology and clinical significance of the restrictive spirometry pattern. Chest. 2016;149(1):238-251.

\section{Publish your work in this journal}

The International Journal of COPD is an international, peer-reviewed journal of therapeutics and pharmacology focusing on concise rapid reporting of clinical studies and reviews in COPD. Special focus is given to the pathophysiological processes underlying the disease, intervention programs, patient focused education, and self management protocols.

\section{Dovepress}

This journal is indexed on PubMed Central, MedLine and CAS. The manuscript management system is completely online and includes a very quick and fair peer-review system, which is all easy to use. Visit $\mathrm{http} / / / \mathrm{www}$.dovepress.com/testimonials.php to read real quotes from published authors. 